\title{
Effects of a 6-week aerobic exercise programme on the cardiovascular parameters, body composition, and quality of life of people living with human immune virus
}

\author{
Davidson Okwudili John ${ }^{1, *}$, Bosede A. Tella², Olajide A. Olawale², Jeneviv N. John ${ }^{3}$ Titilope A. Adeyemo, Obinna C. Okezue ${ }^{3}$ \\ 'Department of Physiotherapy, Federal Teaching Hospital, Abakaliki, Nigeria \\ ${ }^{2}$ Department of Physiotherapy, Faculty of Clinical Sciences, College of Medicine, University of Lagos, Lagos, Nigeria \\ ${ }^{3}$ Department of Medical Rehabilitation, Faculty of Health Sciences and Technology, College of Medicine, University of Nigeria, Nsukka, Nigeria \\ ${ }^{4}$ Department of Haematology, Faculty of Clinical Sciences, College of Medicine, University of Lagos, Lagos, Nigeria
}

This study evaluated the effects of aerobic exercise program on the cardiovascular parameters, body composition, and quality of life $(\mathrm{O} \mathrm{OL})$ of people living with human immune virus (HIV). Patients were recruited from the HIV clinic in a tertiary hospital in Nigeria. Fish bowl method was used to randomize the patients to either experimental or control group. Experimental group received nutritional counseling and aerobic exercise program on a treadmill, 3 times a week for a period of 6 weeks, while the control group received only nutritional counseling. Cardiovascular parameters, aerobic fitness, body composition parameters, and OoL were evaluated at baseline and 6 weeks. Descriptive statistics was used to explore demographic data while the hypothesis was tested using inferential statistics of $t$-test. Alpha level was set at $P<0.05$. The result showed that there was an improvement in cardiovascular parame- ters in both groups, attaining significance in the experimental group $(P=0.000)$. Aerobic fitness increased significantly in experimental group $(P=0.000)$. Body composition decreased significantly while there was a significant difference in the muscle mass $(\%)$ between groups $(P<0.05)$. All domains of $\mathrm{O} \mathrm{L}$ had a significant improvement in both groups $(P<0.005)$. A 6-week aerobic exercise program in addition to nutritional counseling was able to significantly improve cardiovascular fitness, body composition, and QoL in people living with HIV/acquired immune deficiency syndrome. Nutritional counseling alone can bring about an improvement only in QoL parameters.

Keywords: Aerobic exercise, Cardiovascular parameters, Body composition, Quality of life

\section{INTRODUCTION}

People with a human immune virus/acquired immune deficiency syndrome (HIV/AIDS) undergoing highly active antiretroviral therapy (HAART) often present with problems associated with HIV infection and its therapy (Ogalha et al., 2011). These include metabolic changes, body and metabolic modifications, the stigma often associated with AIDS, chronic use of antiretroviral, and fear of imminent death. These problems taken together can affect the physical, social, and psychological health components, causing a negative impact on their quality of life (QoL) (Ogalha et al., 2011). The increased number of people with HIV/AIDS increases the responsibility on the health care system, this shows the increased need to reduce disability level and improve optimal functional status of people living with HIV/AIDS so as to improve their QoL (Anderson, 2006). Exercise is consistently listed among the three most common complementary and alternative therapies utilized by HIV-infected persons to improve their QoL (Cade et al., 2004; Greene et al., 1999; Sparber et al., 2000; Standish et al., 2001). Therapeutic exercise among people with HIV has been shown to be both beneficial and safe (Ciccolo et al., 2004).

The introduction of HAART has led to AIDS becoming a chronic disease, requiring nonphar-macological treatment methods such as therapeutic exercises (O'Brien et al., 2004; Scevola et
${ }^{*}$ Corresponding author: Davidson Okwudili John

(iD) https://orcid.org/0000-0001-8411-0714

Department of Physiotherapy, Federal Teaching Hospital, PMB 102, Abakaliki, Ebonyi State, Nigeria

Tel: +234-8032529550, Fax: +234-8032529550, E-mail: davidsonokwudili@yahoo.com Received: June 16, 2018 / Accepted: August 12, 2018
This is an Open Access article distributed under the terms of the Creative Commons Attribution Non-Commercial License (http://creativecommons.org/licenses/by-nc/4.0/) which permits unrestricted non-commercial use, distribution, and reproduction in any medium, provided the original work is properly cited. 
al., 2003) which maintains functionality and QoL for several years (Gomes et al., 2010). Therefore, maintaining the physical and functional fitness of patients with HIV/AIDS has become one of the most important therapeutic targets, particularly in the case of "wasting syndrome," which is an important loss of muscle mass (Souza et al., 2008). Some studies have shown that the use of aerobic exercise (Ogalha et al., 2011), as well as combined (aerobic and strength) exercise (Scevola et al., 2003) training has brought improvement in the aerobic capacity/functional capacity, body composition, metabolic indices, and QoL of patients with HIV.

Evidence has shown that engaging in physical activity regularly may improve mental health. (Gomes et al., 2010). Therefore, engaging in regular exercise is a valid method of managing the psychological manifestations of HIV infection (Gomes et al., 2010). Previous studies shows that participation in aerobic or strength training programme may lead to improvement in emotional, mental and physical well-being (Lox et al., 1995), and reduction of depressive symptoms (Neidig et al., 2003), thus improving their QoL.

People infected with HIV have shown low aerobic capacities, manifested as reduced ability to utilize oxygen (maximum oxygen uptake, $\mathrm{VO}_{2 \max }$ ) and perform physical work (Keyser et al., 2000). People living with $\mathrm{HIV}$ have $\mathrm{VO}_{2 \max }$ of $24 \%-44 \%$ lower than their age-matched normal values during aerobic capacity functional test ability to utilize oxygen (Lox et al., 1995; MacArthur et al., 1993). While it is possible that the aetiology of this lowered work capacity is multifactorial, the available limited evidence suggests that moderate to high intensity aerobic exercise training is effective in improving the functional aerobic capacity of HIV-positive persons (Hand et al., 2008).

Hypertension is found in around 25\% of people with HIV because of sedentary lifestyles and other increased cardiovascular risk factors (Blanco et al., 2010; Malita et al., 2005). The current recommendation for the treatment of hypertension in HIV patients is the same as in the normal population: lifestyle modifications, including regular exercise, are prescribed with the possible addition of anti-hypertensive drugs if needed (Blanco et al., 2010).

Unfortunately, treating HIV with HAART results in a number of physical and psychological adverse effects. Common physical adverse effects include disorders of the nervous system (headache, neuropathic pain, and fatigue), gastrointestinal tract (diarrhea, vomiting, and nausea), morphology (lipodystrophy and lipidatrophy), integumentary system (dry skin and rash), and metabolic processes (glucose, altered lipid profile, osteoporosis) (Hicks et al., 2003). Possible psychological side effects include agitation, confusion, anxiety, hallucinations, mania and depression (Horwath,
2002). Even though HAART reduces the mortality rate in HIVindividuals, the prolongation of patient's life can be accompanied with a reduction in their QoL (Ciccolo et al., 2004). Therefore, it becomes very necessary to develop protocols or treatment models which aim at enhancing QoL in HIV population.

Hence this study aims to evaluate the aerobic exercise programme effects on the cardiovascular indices, QoL, and body composition of people living with HIV.

\section{MATERIALS AND METHODS}

\section{Research design}

The study is a pretest-posttest controlled randomized design.

\section{Subject selection}

A total of 60 subjects were recruited from the AIDS Prevention and Intervention Initiative clinic of a teaching hospital (Fig. 1) Subjects were consecutively invited to enter the protocol. They were randomly assigned to either experimental or control group. Simple random sampling using fish bowl method where numbers were written on cards and draws were made was used. Inclusion criteria were subjects currently on Active Retroviral drugs, age 18 years and above, availability to attend the study activities. Exclusion criteria were pregnant subjects, subjects contra indicated to exercise testing and training (American College of Sports Medicine, 2010), significant cognitive impairment, involvement in a regular exercise program (defined as two or more structured exer-

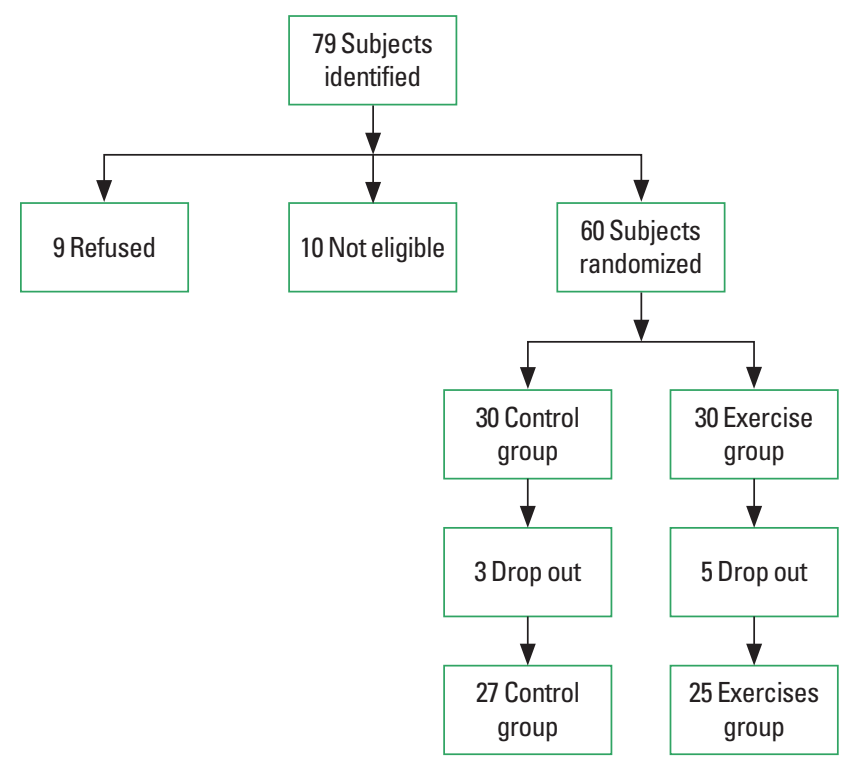

Fig. 1. Flow chart showing process of subject enrollment. 
cise sessions weekly for more than, or equal to 6 months prior to enrollment).

\section{Instrumentation}

\section{Medical outcomes study HIV health survey (MOS-HIV health survey)}

The MOS-HIV survey (English version) was used to assess aspects of health-related QoL (Wu et al., 1991). It has a good reliability and validity in populations with HIV (Burgess et al., 1993). The questionnaire consists of 35 items. It covers 10 dimensions of health and one item covering health transition. Subscales are scored as a summated rating on a 0-100 scale with a higher score representing better health-related QoL. The questionnaire was administered to all the subjects at baseline and at the sixth week.

\section{American Heart Association - American College of Sports Medicine preparticipation screening questionnaire}

This was developed by the American College of Sports Medicine Position Stand and American Heart Association (1998), to screen for cardiovascular risk factors and readiness to exercise before the individual commences an exercise programme. The questionnaire contains three sections. Section one assesses for history of cardiovascular disease, section two assesses for symptoms, section three assesses for cardiovascular risk factors. The experimental group was screened with this instrument before starting the exercise regimen.

\section{Treadmill exercise}

A motor driven treadmill ergometer (KL001, Daily Youth Sports Product Co., Ltd., Guangzhou, China) was used to exercise the subjects.

\section{Tape rule}

A nonelastic tape measure (HD2020, Sanghai Kearing Stationary Co., Ltd., Shanghi, China) of range $0-150 \mathrm{~cm}$ was used to measure the waist circumference (WC).

\section{Body composition monitor}

An OMRON body composition monitor (BF 511, Daily Youth Sports Product Co., Ltd.) was used to measure the body composition. OMRON BF511 consists of the main unit and the display unit. The main unit has two pairs of foot electrodes while the display unit has two pairs of grip electrodes for the hands, a display screen and display buttons. A cord connects the display unit to the main unit. The OMRON BF511 measures the body fat (BF) percentage by the bioelectrical impedance (BI) method. It measures the following body composition parameters: $\mathrm{BF}$ (in \%), visceral fat (VF) (up to 30 levels), body mass index (BMI) and skeletal muscle (in \%)

\section{Height meter}

A standiometer was used to measure subject's height in meter.

\section{Sphygmomanometer and stethoscope}

This was used to measure systolic blood pressure (SBP), diastolic blood pressure (DBP), and heart rate (HR).

\section{Procedure}

An ethical approval was obtained from the institutional Research and Ethics Committee (Ref No.: ADM/DCST/HREC/VOL.XVI/ APP/452). An informed consent form was also obtained from the subjects prior to participation.

\section{Body composition}

Height was measured in meter $(\mathrm{m})$ using a standiometer with subjects barefoot. Weight $(\mathrm{kg})$ was measured using OMRON BF511, with the subject stepping on the main unit barefooted and placing the feet on the foot electrodes with the weight evenly distributed in an upright position. BMI was measured with OMRON BF511 which uses the height information stored in the personal profile or when entering the guest mode and weight measurement to calculate the BMI $\left(\mathrm{kg} / \mathrm{m}^{2}\right)$. The device uses the $\mathrm{BI}$ to estimate the BF percentage and VF percentage In order for the scale to determine body composition, it uses the electrical impedance, along with height, weight, age and gender information to generate results based on OMRON's data of body composition. The device also calculates the body skeletal muscle mass. WC in centimeter was measured at the level of the navel at the end of gentle expiration, with the subject in an upright position, measure with a flexible tape extendable to one decimal place (Jackson and Pollock, 1978). The values were taken at baseline and at 6 weeks. All measurement was taken by one researcher to avoid inter rater error.

\section{Exercise training}

Subjects were grouped into 5-8 subjects for ease of supervision by the researchers and were screened for cardiovascular risk factors. After being certified fit for exercise, the baseline blood pressure and HR was taken. 
Aerobic exercise training was performed on a motor driven treadmill ergometer using a ramp protocol. Exercise was performed 3 times per week at a moderate intensity level for maximum of $45 \mathrm{~min}$. Exercise was started with initial brisk walking pace, ranging from $1.5-2.0 \mathrm{mph}$ at a $0 \%$ grade for $4 \mathrm{~min}$ to raise the HR within $40 \%-50 \%$ of predicted age maximum (220-age) (ACSM, 2010). This was followed by a second 4-min stage, retaining the same speed, but the treadmill was raised to a $5 \%$ grade. The speed was increased as the training progresses until the target HR $75 \%$ of the predicted maximum was reached. Exercise was monitored using Borg Perceived Rate of Exertion Scale. Participants were instructed to rate their perceived exertion (Borg, 1982). Measurement of blood pressure and HR were taken every 3 min as an additional monitor. The $\mathrm{VO}_{2 \max }$ was calculated using the equation:

$\mathrm{VO}_{2 \max }=15.1+(21.8 \times$ speed $)-(0.327 \times \mathrm{HR})-(0.263 \times$ speed $\times$ age $)+(0.00504 \times \mathrm{HR} \times$ age $)+(5.98 \times$ gender $)$. Treadmill speed in $\mathrm{mph}$; gender $=0$ for females, 1 for males (ACSM, 2010; Ebbeling et al., 1991). Measurement of resting HR and blood pressure were also taken. All the parameters were measured at baseline and 6 weeks.

\section{Quality of life}

HIV-MOS health survey was used to measure the domains of QoL at baseline and at 6 weeks. The scoring of the subscales was done as a summated rating on a standardized scale of $0-100$.

\section{Data analysis}

Descriptive statistics of mean, standard deviation and percent-

Table 1. Demographic data of control and experimental group

\begin{tabular}{lcc}
\hline Variable & Control & Intervention \\
\hline Age (yr) & $40.9 \pm 8$ & $41 \pm 7.8$ \\
Gender & $11(40.7)$ & \\
Male & $16(59.3)$ & $17(62.0)$ \\
Female & $1: 1.5$ & $1: 2.1$ \\
Ratio, male:female & & \\
Marital status & $10(37.0)$ & $7(28.0)$ \\
Single & $17(63.0)$ & $18(72.0)$ \\
Married & & \\
Educational level & $0(0)$ & $0(0)$ \\
Primary & $16(59.3)$ & $18(72.0)$ \\
Secondary & $11(40.7)$ & $7(28.0)$ \\
Tertiary & $1.62 \pm 0.74$ & $1.6 \pm 0.09$ \\
Height $(\mathrm{m})$ &
\end{tabular}

Values are presented as mean \pm standard deviation or number (\%). ages was used to summarize data. Shapiro-Wilk $W$-test was used to test and confirm that the data was normally distributed. Unpaired $t$-test was used to compare the mean differences of variables between the groups. The differences between mean values were expressed at a confidence interval of $95 \%$. All survey data were analyzed by using SPSS ver. 16.0 (SPSS Inc., Chicago, IL, USA).

\section{RESULTS}

A total of 60 subjects were randomized ( 30 in each group). After randomization, 5 subjects dropped out of the experimental group without reaching $70 \%$ percent of completion. Three subjects dropped out of control group. All parameters were taken at

Table 2. Between group comparison of cardiovascular parameters

\begin{tabular}{lcccc}
\hline Variable & $\begin{array}{c}\text { Study group } \\
(\mathrm{n}=30)\end{array}$ & $\begin{array}{c}\text { Control group } \\
(\mathrm{n}=28)\end{array}$ & t-value & $P$-value \\
\hline Pre & & & & \\
SBP & $123 \pm 15.78$ & $125 \pm 15.67$ & -5.525 & 0.661 \\
DBP & $77 \pm 10.52$ & $78.9 \pm 10.49$ & -3.280 & 0.701 \\
HR & $77.6 \pm 10.79$ & $78.97 \pm 10.83$ & -2.423 & 0.164 \\
VO2max & $41.4 \pm 5.73$ & $40.5 \pm 4.17$ & 0.643 & 0.525 \\
Post & & & & \\
SBP (mmHg) & $77.47 \pm 13.38$ & $124.20 \pm 14.54$ & -7.888 & $0.001^{*}$ \\
DBP (mmHg) & $71.3 \pm 6.11$ & $77.7 \pm 9.79$ & -7.055 & $0.001^{*}$ \\
HR (bpm) & $72.40 \pm 6.63$ & $78.03 \pm 10.01$ & -6.055 & $0.001^{*}$ \\
VO ${ }_{2 \max }$ & $65 \pm 9.05$ & $40.60 \pm 4.24$ & 12.75 & $0.001^{*}$ \\
\hline
\end{tabular}

Values are presented as mean \pm standard deviation.

$\mathrm{SBP}$, systolic blood pressure; DBP, diastolic blood pressure; $\mathrm{HR}$, heart rate; $\mathrm{VO}_{2 \max }$ maximum oxygen consumption.

*Significance between groups at $P<0.05$.

Table 3. Within group comparison of cardiovascular parameters

\begin{tabular}{lcccl}
\hline Variable & Pre & Post & $t$-value & $P$-value \\
\hline Study group & & & & \\
SBP (mmHg) & $123 \pm 15.79$ & $117 \pm 13.36$ & 6.378 & $0.001^{*}$ \\
DBP (mmHg) & $76 \pm 10.77$ & $71 \pm 6.10$ & 5.051 & $0.001^{*}$ \\
HR (bpm) & $78 \pm 11.29$ & $72 \pm 6.63$ & 4.716 & $0.001^{*}$ \\
VO ${ }_{2 \max }$ & $41.4 \pm 5.73$ & $65 \pm 9.05$ & -20.376 & $0.001^{*}$ \\
Control group & & & & \\
SBP (mmHg) & $125 \pm 15.39$ & $124 \pm 14.54$ & 4.350 & 0.062 \\
DBP (mmHg) & $79 \pm 10.50$ & $78 \pm 9.79$ & 3.714 & 0.0781 \\
HR (bpm) & $79 \pm 10.83$ & $78 \pm 10$ & 3.080 & 0.124 \\
VO ${ }_{2 \max }$ & $40 \pm 4.17$ & $40.6 \pm 4.24$ & -0.279 & 0.782 \\
\hline
\end{tabular}

Values are presented as mean \pm standard deviation.

$\mathrm{SBP}$, systolic blood pressure; DBP, diastolic blood pressure; $\mathrm{HR}$, heart rate; $\mathrm{VO}_{2 \max }$ maximum oxygen consumption.

*Significance within group at $P<0.05$. 
Table 4. Between group comparison of body composition parameters

\begin{tabular}{lcccc}
\hline Variable & $\begin{array}{c}\text { Study group } \\
(\mathrm{n}=30)\end{array}$ & $\begin{array}{c}\text { Control group } \\
(\mathrm{n}=28)\end{array}$ & $t$-value & $P$-value \\
\hline Pre & & & & \\
$\mathrm{BMI}\left(\mathrm{kg} / \mathrm{m}^{2}\right)$ & $27.39 \pm 4.25$ & $27.35 \pm 5.10$ & 0.039 & 0.969 \\
$\mathrm{BF}(\%)$ & $30.52 \pm 10.56$ & $30.92 \pm 9.92$ & -0.399 & 0.693 \\
VF $(\%)$ & $6.9 \pm 1.61$ & $7.93 \pm 1.64$ & -2.079 & $0.047^{*}$ \\
WC $(\mathrm{cm})$ & $82.53 \pm 8.58$ & $81.5 \pm 8.58$ & 0.444 & 0.661 \\
Muscle $(\%)$ & $30.45 \pm 6.87$ & $29.95 \pm 6.59$ & 0.280 & 0.781 \\
Post & & & & \\
BMI $\left(\mathrm{kg} / \mathrm{m}^{2}\right)$ & $23.37 \pm 3.55$ & $27.2 \pm 5.10$ & 0.997 & $0.002^{*}$ \\
BF $(\%)$ & $27 \pm 10$ & $30.6 \pm 10.10$ & -4.053 & $0.042^{*}$ \\
VF $(\%)$ & $6 \pm 1.37$ & $7.59 \pm 1.68$ & -3.763 & $0.001^{*}$ \\
WC $(\mathrm{cm})$ & $77.1 \pm 6.59$ & $81.27 \pm 8.49$ & -3.663 & $0.002^{*}$ \\
Muscle $(\%)$ & $31.75 \pm 6.46$ & $29.59 \pm 6.47$ & 2.460 & $0.001^{*}$ \\
\hline
\end{tabular}

Values are presented as mean \pm standard deviation.

$\mathrm{BMl}$, body mass index; $\mathrm{BF}$, body fat; $\mathrm{VF}$, visceral fat; $\mathrm{WC}$, waist circumference.

${ }^{*}$ Significance between groups at $P<0.05$.

Table 5. Within group comparison of body composition parameters

\begin{tabular}{lcccc}
\hline Variable & Pre & Post & t-test & $P$-value \\
\hline Study group & & & & \\
BMl $\left(\mathrm{kg} / \mathrm{m}^{2}\right)$ & $27.39 \pm 4.25$ & $23.37 \pm 5.55$ & 4.502 & $0.001^{*}$ \\
WC $(\mathrm{cm})$ & $82.5 \pm 8.58$ & $77.1 \pm 6.59$ & 6.168 & $0.001^{*}$ \\
VF $(\%)$ & $6.9 \pm 1.61$ & $6 \pm 1.37$ & -7.801 & 0.701 \\
BF $(\%)$ & $30.5 \pm 6.87$ & $27 \pm 10$ & 6.400 & $0.001^{*}$ \\
Muscle $(\%)$ & $30.4 \pm 6.87$ & $34.75 \pm 4.02$ & -6.196 & $0.001^{*}$ \\
Control group & & & & \\
BMl (kg/m $\left./ \mathrm{m}^{2}\right)$ & $27.3 \pm 5.08$ & $27.2 \pm 5.10$ & 0.096 & 0.960 \\
WC $(\mathrm{cm})$ & $81.5 \pm 8.53$ & $81.27 \pm 8.49$ & 1.523 & 0.961 \\
VF $(\%)$ & $7.93 \pm 1.64$ & $7.59 \pm 1.68$ & 0.208 & 0.680 \\
BF $(\%)$ & $30.92 \pm 9.92$ & $30.6 \pm 10$ & 1.494 & 0.680 \\
Muscle $(\%)$ & $29.95 \pm 6.59$ & $29.76 \pm 6.50$ & 0.417 & 0.680 \\
\hline
\end{tabular}

Values are presented as mean \pm standard deviation.

$\mathrm{BMI}$, body mass index; $\mathrm{BF}$, body fat; $\mathrm{VF}$, visceral fat; $\mathrm{WC}$, waist circumference.

* Significance within group at $P<0.05$.

baseline and at sixth week. All result were analyzed using a confidence interval of $95 \%$ and $P<0.05$. Table 1 summarized the demographic characteristics of both the control and experimental group.

Between group comparison at 6 weeks shows that a significant difference exists in SBP, DBP, and resting HR at $(P=0.001)$ (Table 2). However, within group comparison (Table 3 ) showed a significant difference in SBP, DBP, and resting HR $(P=0.001)$ in the experimental group. Post intervention comparison between the groups shows that a significant difference exists in all the parameters: BMI, BF, VF, WC, muscle mass at $P=0.002, P=0.042, P=$
Table 6. Between group comparison of quality of life scores

\begin{tabular}{lcccc}
\hline Variable & $\begin{array}{c}\text { Study group } \\
(\mathrm{n}=30)\end{array}$ & $\begin{array}{c}\text { Control group } \\
(\mathrm{n}=28)\end{array}$ & $t$-value & $P$-value \\
\hline Pre & & & & \\
General health & $26.17 \pm 5.68$ & $21.17 \pm 6.11$ & -0.612 & 0.545 \\
Physical functioning & $38.97 \pm 4.97$ & $40.1 \pm 5.33$ & -2.152 & 0.060 \\
Role functioning & $20 \pm 24.90$ & $25 \pm 25.43$ & -0.828 & 0.415 \\
Cognitive functioning & $42.7 \pm 17.90$ & $34.83 \pm 9.10$ & 1.932 & 0.063 \\
Mental health & $23.77 \pm 11.33$ & $27.33 \pm 11.43$ & -1.426 & 0.164 \\
Energy/vitality & $26.67 \pm 5.46$ & $29.5 \pm 8.13$ & -1.598 & 0.121 \\
Post & & & & \\
General health & $51.33 \pm 3.93$ & $35 \pm 5.41$ & 13.927 & $0.001^{*}$ \\
Physical functioning & $92.47 \pm 6.45$ & $67.1 \pm 9.00$ & 12.868 & $0.001^{*}$ \\
Role functioning & $73.33 \pm 31.44$ & $41.67 \pm 32.37$ & 3.898 & $0.001^{*}$ \\
Cognitive functioning & $100 \pm 0.00$ & $72.67 \pm 8.17$ & 18.320 & $0.001^{*}$ \\
Mental health & $71.37 \pm 3.71$ & $60.37 \pm 6.67$ & 9.090 & $0.001^{*}$ \\
Energy/vitality & $59.67 \pm 4.72$ & $47 \pm 7.38$ & 8.382 & $0.001^{*}$ \\
\hline
\end{tabular}

Values are presented as mean \pm standard deviation.

${ }^{*}$ Significance within group at $P<0.05$.

Table 7. Within group comparison of quality of life scores

\begin{tabular}{lcccc}
\hline Variable & Pre & Post & $t$-value & $P$-value \\
\hline Study group & & & & \\
General health & $26.2 \pm 5.68$ & $51.3 \pm 3.93$ & -20.796 & $0.001^{*}$ \\
Physical functioning & $37.3 \pm 4.98$ & $92.5 \pm 6.45$ & -55.559 & $0.001^{*}$ \\
Role functioning & $20 \pm 24.91$ & $73 \pm 31.44$ & -7.899 & $0.001^{*}$ \\
Cognitive functioning & $42.7 \pm 17.90$ & $100 \pm 00$ & -17.523 & $0.001^{*}$ \\
Mental health & $23.8 \pm 11.30$ & $71.4 \pm 3.71$ & -21.682 & $0.001^{*}$ \\
Energy/vitality & $26.7 \pm 5.47$ & $59.7 \pm 4.72$ & -26.690 & $0.001^{*}$ \\
Control group & & & & \\
General health & $27.2 \pm 6.10$ & $35 \pm 5.41$ & -6.861 & $0.001^{*}$ \\
Physical functioning & $40 \pm 5.33$ & $67 \pm 9.03$ & -14.628 & $0.001^{*}$ \\
Role functioning & $25 \pm 25.43$ & $41.7 \pm 32.39$ & -3.340 & $0.001^{*}$ \\
Cognitive functioning & $34.8 \pm 9.05$ & $72.67 \pm 8.17$ & -19.776 & $0.001^{*}$ \\
Mental health & $27 \pm 11.43$ & $60.4 \pm 6.67$ & -16.938 & $0.001^{*}$ \\
Energy/vitality & $29.5 \pm 8.10$ & $47 \pm 7.38$ & 8.5558 & $0.001^{*}$ \\
\hline
\end{tabular}

Values are presented as mean \pm standard deviation.

*Significance within group at $P<0.05$.

$0.001, P=0.002$, and $P=0.001$, respectively (Table 4). In the experimental group, there was a significant difference in all the body composition parameters except VF at $P=0.001$ (Table 5). A significant difference was attained in all the QoL domains after the intervention period at $P=0.001$ (Table 6). There was also a significant difference in within group comparison of all the measured QoL life domains in both the control and experimental group (Table 7). 


\section{DISCUSSION}

The study showed that a 6-week aerobic exercise intervention in HIV subjects can lead to an appreciable improvement in cardiovascular parameters, body composition and QoL.

The study demonstrated a $16 \%$ drop-out rate, which is less than the findings of a meta-analysis on aerobic exercise and HIV/ AIDS, in which six studies reported drop-out rates higher than $20 \%$ and two others higher than $50 \%$ (O'Brien et al., 2004). The observed lower dropout rate may be as a result of the constant text messages sent to the subjects reminding them of the importance to attend the exercise and nutritional counseling sessions. The subjects were also given some stipends.

However, the study subjects achieved higher completion rates $(80 \%)$ than that reported for three similar exercise intervention trials (70\%, 77\%, and 78\%, respectively) (Hand et al., 2008; Roubenoff et al., 2002) and less than the rate (81\%) reported by another study (Fillipas et al., 2006). This may also be as a result of some musculoskeletal symptomatic relief such as reduced pain at the muscle and joints, and improved endurance as was reported by the subjects during the first two weeks of the exercise program may have motivated them to adhere to the exercise program.

There was an improvement (decrease) in cardiovascular parameters (SBP, DBP, HR) in the control group, though it did not attain significance. However, there was also a significant improvement (decrease) in cardiovascular parameters in the experimental group. There was also a significant improvement (decrease) in the cardiovascular parameters between the control and experimental group. This shows an improved cardiovascular fitness resulting from both supervised (intervention) and nutritional program. The result is in line with a similar findings of improved cardiovascular fitness, evidenced in the resting heart of $20 \mathrm{bpm}$ difference between the supervised aerobic and resistance exercise group and the unsupervised walking program (Ciccolo et al., 2004), and another study in brazil by Ogalha et al. (2011) showing a significant change (decrease) in resting HR of intervention group using aerobic and resistance exercise training in HIV subjects. This is encouraging since impaired physical endurance is frequently observed in this population.

Furthermore, cardiorespiratory fitness $\left(\mathrm{VO}_{2 \max }\right)$ improved significantly in the experimental group compared to the control group. This is in agreement with the findings of Mutimura et al. (2008), using functional capacity to predict $\mathrm{VO}_{2 \max }$ after a Shuttle test. There was an improvement of $\mathrm{VO}_{2 \max }$ in the intervention group compared to the control group. The improved $\mathrm{VO}_{2 \max }$ is an important measure of aerobic capacity related to health and longevity (Manson et al., 1999; Myers et al., 2002). HIV individuals may have up to $9 \%$ lower $\mathrm{VO}_{2 \max }$ values, compared to agematched healthy individuals (Johnson et al., 1990). In contrast to the above results, others have found nonsignificant $9 \%-10 \%$ increases in $\mathrm{VO}_{2 \max }$ following a combined training protocol after 12 and 16 weeks in HIV infected individuals (Robinson et al., 2007).

More so, within group analysis of body composition parameters showed a significant improvement (decrease) in the body composition parameters (WC, BMI, body and muscle mass) $(P<0.05)$ in the experimental group. Body composition parameters also improved significantly between groups $(P<0.05)$. VF showed no significant change within group but significantly decreased when compared between group $(P=0.001)$. Since HIV-infected individuals receiving HAART are at risk for greater fat (subcutaneous and visceral) accumulation which may positively influence WC, they represent a population at greater risk for metabolic abnormalities linked to cardiovascular disease and diabetes. Therefore, the reductions in $\mathrm{WC}$ and percentage $\mathrm{BF}$ were significant in the experimental group and may be a marker for decreased risk of metabolic diseases associated with abdominal obesity. The result is agreement with the result from Ogalha et al. (2011) who found a significant decrease in both $\mathrm{BMI}, \mathrm{BF}$, and muscle mass (increase) in a study to evaluate the impact of regular physical activity on HIV patients. Fillipas et al. (2006) in a similar study of longer duration (6 months) reported a significant increase in muscle area $\left(6 \pm 1 \mathrm{~cm}^{2}\right.$ vs. $\left.2 \pm 1 \mathrm{~cm}^{2}, P=0.02\right)$ and WC (decrease) compared with the control group.

In addition to negative physical and physiological changes, HIV-infected patients receiving HAART can also experience psychological responses such as agitation, confusion, anxiety, nightmares, mania, and depression. The experimental and control groups showed significant increase in the QoL scores. This significance exists both within and between groups, but the change is more in the experimental group. The experimental subjects reported substantial improvements in both physical and mental QoL scales ( 55 points and 48 points, respectively) while the control subjects had lower scores on the same scales (27 points and 33 points, respectively). This indicates that the subjects reported improvements in performing daily activities such as bathing, dressing, walking, climbing stairs, and carrying groceries, which are activities captured in the physical QoL scale.

Furthermore, higher mental QoL scores observed in the experimental group indicate improved mental health with aerobic exercise and lower risk of depression (Stoll et al., 2001). This result 
strongly agree with the findings of Ogalha et al. (2011) in a related study which revealed a marked improvement in QoL domains both in the exercise and nonexercise group. Ciccolo et al. (2004) and Fillipas et al. (2006) also found that QoL domain improved significantly in HIV subjects using exercise intervention.

It is of importance to remark that from the result of this study all subjects received a clear benefit in terms of QoL evaluation, even those who were assigned to counseling sessions only. This fact suggests that the simple participation in an educational activity can promote a significant increase in $\mathrm{QoL}$ of patients with HIV/AIDS. A 6-week aerobic exercise intervention coupled with nutritional guidance in people living with HIV/AIDS was able to significantly improve cardiovascular fitness, body composition and QoL. Nutritional counseling alone can bring about an improvement only in QoL in people living with HIV/AIDS.

Future trials should focus upon longer duration exercise programs for enhancing the general health status of individuals. It would be relevant to specifically target HIV patients of lower socio economic status, since they represent individuals with greater susceptibility to disease progression and premature mortality (Cunningham et al., 2010). Studies with follow-up for longer duration is required to define the duration of such effects and the need of a periodical "booster" to keep the benefits over time. It is important to include supervised exercise as a routine in HIV/ AIDS clinics. Physiotherapist should be involved in HIV/AIDS intervention programs for supervised exercise programs and management of other musculoskeletal impairment.

\section{CONFLICT OF INTEREST}

No potential conflict of interest relevant to this article was reported.

\section{REFERENCES}

American College of Sports Medicine. ACSM's guidelines for graded exercise testing and prescription. 8th ed. Philadelphia (PA): Lippincott Williams \& Wilkins; 2010

American College of Sports Medicine Position Stand and American Heart Association. Recommendations for cardiovascular screening, staffing, and emergency policies at health/fitness facilities. Med Sci Sports Exerc 1998;30:1009-1018.

Anderson SL. Physical therapy for HIV/AIDS patients. Cardiopulm Phys Ther J 2006;17:59-62.

Blanco F, San Román J, Vispo E, López M, Salto A, Abad V, Soriano V.
Management of metabolic complications and cardiovascular risk in HIV-infected patients. AIDS Rev 2010;12:231-241.

Borg GA. Psychophysical bases of perceived exertion. Med Sci Sports Exerc 1982;14:377-381.

Burgess A, Dayer M, Catalan J, Hawkins D, Gazzard B. The reliability and validity of two HIV-specific health-related Quality-of-Life measures: a preliminary analysis. AIDS 1993;7:1001-1008.

Cade WT, Peralta L, Keyser RE. Aerobic exercise dysfunction in human immunodeficiency virus: a potential link to physical disability. Phys Ther 2004;84:655-664.

Ciccolo JT, Jowers EM, Bartholomew JB. The benefits of exercise training for quality of life in HIV/AIDS in the post-HAART era. Sports Med 2004;34:487-499.

Cunningham AL, Donaghy H, Harman AN, Kim M, Turville SG. Manipulation of dendritic cell function by viruses. Curr Opin Microbiol 2010; 13:524-529.

Ebbeling CB, Ward A, Puleo EM, Widrick J, Rippe JM. Development of a single-stage submaximal treadmill walking test. Med Sci Sports Exerc 1991;23:966-973.

Fillipas S, Oldmeadow LB, Bailey MJ, Cherry CL. A six-month, supervised, aerobic and resistance exercise program improves self-efficacy in people with human immunodeficiency virus: a randomised controlled trial. Aust J Physiother 2006;52:185-190.

Gomes RD, Borges JP, Lima DB, Farinatti PT. Effects of physical exercise in the perception of life satisfaction and immunological function in HIV-infected patients: non-randomized clinical trial. Rev Bras Fisioter 2010;14:390-395.

Greene KB, Berger J, Reeves C, Moffat A, Standish LJ, Calabrese C. Most frequently used alternative and complementary therapies and activities by participants in the AMCOA study. J Assoc Nurses AIDS Care 1999;10:60-73.

Hand GA, Phillips KD, Dudgeon WD, William Lyerly G, Larry Durstine J, Burgess SE. Moderate intensity exercise training reverses functional aerobic impairment in HIV-infected individuals. AIDS Care 2008;20: 1066-1074.

Hicks C, Currier J, Sax P, Sherer R, Wanke C. Current management challenges in HIV: tolerability of antiretrovirals and metabolic complications. AIDS Patient Care STDS 2003;17:221-233.

Horwath E. Psychiatric and neuropsychiatric manifestations of HIV infection. J Int Assoc Physicians AIDS Care (Chic) 2002;1 Suppl 1:S1-15.

Jackson AS, Pollock ML. Generalized equations for predicting body density of men. Br J Nutr 1978;40:497-504.

Johnson JE, Anders GT, Blanton HM, Hawkes CE, Bush BA, McAllister CK, Matthews JI. Exercise dysfunction in patients seropositive for the human immunodeficiency virus. Am Rev Respir Dis 1990;141:618- 
622.

Keyser RE, Peralta L, Cade WT, Miller S, Anixt J. Functional aerobic impairment in adolescents seropositive for HIV: a quasiexperimental analysis. Arch Phys Med Rehabil 2000;81:1479-1484.

Lox CL, McAuley E, Tucker RS. Exercise as an intervention for enhancing subjective well-being in an HIV-1 population. J Sport Exerc Psychol 1995;17:345-362.

MacArthur RD, Levine SD, Birk TJ. Supervised exercise training improves cardiopulmonary fitness in HIV-infected persons. Med Sci Sports Exerc 1993;25:684-688.

Malita FM, Karelis AD, Toma E, Rabasa-Lhoret R. Effects of different types of exercise on body composition and fat distribution in HIV-infected patients: a brief review. Can J Appl Physiol 2005;30:233-245.

Manson JE, Hu FB, Rich-Edwards JW, Colditz GA, Stampfer MJ, Willett WC, Speizer FE, Hennekens CH. A prospective study of walking as compared with vigorous exercise in the prevention of coronary heart disease in women. N Engl J Med 1999;341:650-658.

Mutimura E, Stewart A, Crowther NJ, Yarasheski KE, Cade WT. The effects of exercise training on quality of life in HAART-treated HIV-positive Rwandan subjects with body fat redistribution. Qual Life Res 2008; 17:377-385.

Myers J, Prakash M, Froelicher V, Do D, Partington S, Atwood JE. Exercise capacity and mortality among men referred for exercise testing. N Engl J Med 2002;346:793-801.

Neidig JL, Smith BA, Brashers DE. Aerobic exercise training for depressive symptom management in adults living with HIV infection. J Assoc Nurses AIDS Care 2003;14:30-40.

O'Brien K, Nixon S, Tynan AM, Glazier RH. Effectiveness of aerobic exercise in adults living with HIV/AIDS: systematic review. Med Sci Sports Exerc 2004;36:1659-1666.

Ogalha C, Luz E, Sampaio E, Souza R, Zarife A, Neto MG, Netto E, Brites

C. A randomized, clinical trial to evaluate the impact of regular physi- cal activity on the quality of life, body morphology and metabolic parameters of patients with AIDS in Salvador, Brazil. J Acquir Immune Defic Syndr 2011;57 Suppl 3:S179-185.

Robinson FP, Quinn LT, Rimmer JH. Effects of high-intensity endurance and resistance exercise on HIV metabolic abnormalities: a pilot study. Biol Res Nurs 2007;8:177-185.

Roubenoff R, Schmitz H, Bairos L, Layne J, Potts E, Cloutier GJ, Denry F. Reduction of abdominal obesity in lipodystrophy associated with human immunodeficiency virus infection by means of diet and exercise: case report and proof of principle. Clin Infect Dis 2002;34:390-393.

Scevola D, Di Matteo A, Lanzarini P, Uberti F, Scevola S, Bernini V, Spoladore G, Faga A. Effect of exercise and strength training on cardiovascular status in HIV-infected patients receiving highly active antiretroviral therapy. AIDS 2003;17 Suppl 1:S123-129.

Souza PM, Jacob-Filho W, Santarém JM, Silva AR, Li HY, Burattini MN. Progressive resistance training in elderly HIV-positive patients: does it work? Clinics (Sao Paulo) 2008;63:619-624.

Sparber A, Wootton JC, Bauer L, Curt G, Eisenberg D, Levin T, Steinberg $\mathrm{SM}$. Use of complementary medicine by adult patients participating in HIV/AIDS clinical trials. J Altern Complement Med 2000;6:415-422.

Standish LJ, Greene KB, Bain S, Reeves C, Sanders F, Wines RC, Turet P, Kim JG, Calabrese C. Alternative medicine use in HIV-positive men and women: demographics, utilization patterns and health status. AIDS Care 2001;13:197-208.

Stoll T, Kauer Y, Büchi S, Klaghofer R, Sensky T, Villiger PM. Prediction of depression in systemic lupus erythematosus patients using SF-36 Mental Health scores. Rheumatology (Oxford) 2001;40:695-698.

Wu AW, Rubin HR, Mathews WC, Ware JE Jr, Brysk LT, Hardy WD, Bozzette SA, Spector SA, Richman DD. A health status questionnaire using 30 items from the Medical Outcomes Study. Preliminary validation in persons with early HIV infection. Med Care 1991;29:786-798. 